\title{
BMJ Open Primary care management of headaches and how direct-access MRI fits: a qualitative study of UK general practitioners' views
}

\author{
Raphael Underwood, ${ }^{1}$ Rachael Kilner, ${ }^{2}$ Leone Ridsdale ${ }^{1}$
}

To cite: Underwood R, Kilner R, Ridsdale L. Primary care management of headaches and how direct-access MRI fits: a qualitative study of UK general practitioners' views. BMJ Open 2017;7:e018169. doi:10.1136/ bmjopen-2017-018169

- Prepublication history for this paper is available online. To view please visit the journal online (http://dx.doi.org/10. 1136/bmjopen-2017-018169).

Received 13 June 2017 Revised 1 September 2017 Accepted 18 September 2017

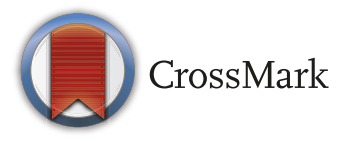

${ }^{1}$ Department of Basic and Clinical Neuroscience, Institute of Psychiatry, Psychology \& Neuroscience, King's College London, London, UK

${ }^{2}$ South Lambeth Road Practice, London, UK

Correspondence to Dr Raphael Underwood; raphael.underwood@kcl.ac.uk

\section{ABSTRACT}

Objectives To develop a better understanding of general practitioners' (GPs) views and experiences of the management of patients with headaches and use of direct-access MRI scans, and observe outcomes of an educational session offered by a GP with a special interest (GPwSI) to GPs.

Design A qualitative study using semistructured interviews, analysed using thematic analysis. A GPwSI in headaches visited practices delivering a talk on headache medication, diagnosis and management.

Setting Sixteen (16) primary care family practices in South London, UK.

Participants Twenty (20) GPS.

Results Not all GPs were aware of the availability of direct-access MRI, but all acknowledged having used referral or direct scans to manage patients' concern about their headaches. A normal scan result helped resolve uncertainty for patient and GP and helped management towards discussion of preventative treatment. However, patients with psychological and/or severe headache symptoms could not necessarily be reassured. GPs reported difficulty interpreting radiology reports, particularly incidental abnormalities. Those who received the educational talk gained knowledge in diagnosis and medication, improving their confidence in management. Conclusions Increased access to imaging, training in headache management, addressing physical and psychological symptoms and standardised reporting of scans may improve GPs' use of direct-access MRI in the future.

\section{INTRODUCTION}

Headache disorders, such as migraine and chronic daily headache, are among the most disabling conditions globally. ${ }^{1}$ In the UK, the majority of people self-manage, but around $3 \%$ of adults consult their general practitioner (GP) for headache every year. ${ }^{2}$ Two per cent of those seen in primary care are referred to a neurologist. ${ }^{2}$ GPs refer patients with headaches to neurologists mainly for a brain scan. ${ }^{3}$ Neuroimaging in headache may be used for multiple reasons and can, for example, identify Chiari malformations. However, patients
Strengths and limitations of this study

- A qualitative study using semistructured interviews provided detailed views from participants.

- These in-depth interviews yielded candid, personal perspectives from clinicians working in busy London practices.

- The findings are specific to the UK healthcare system, thus requiring replication in other healthcare systems.

- Only a small number of participants took part in the educational intervention, limiting the ability to draw out generalisable outcomes.

pressuring for a scan typically worry their headache symptoms have a life-threatening cause, such as a brain tumour. ${ }^{34}$ The likelihood of headache consulters having a brain tumour is low, estimated at 1 in $1000 .{ }^{5}{ }^{6} \mathrm{~A}$ normal scan result may reassure worried patients. $^{78}$

Headaches are the most common reason for referral to a neurologist, accounting for at least $21 \%$ of new neurology appointments, ${ }^{9}$ resulting in service and opportunity costs. ${ }^{10}$ The UK has fewer neurologists for the population than other Western countries, ${ }^{11}$ making it more important to limit unnecessary referring. Providing direct access to scanning for GPs may reduce demand for referrals, as well as costs. ${ }^{12}$ One retrospective and one prospective study found that direct access to CT scans reduced costs by reducing referrals to secondary care and follow-up appointments with the GP. ${ }^{12}{ }^{13}$ A retrospective study of direct-access MRI scans also found that costs were reduced for this pathway, relative to the neurology referral pathway. ${ }^{14}$ Furthermore, a randomised controlled trial (RCT) of MRI scans offered to anxious patients in a headache clinic found that scans for reassurance resulted in lower service use and thus reduced costs. ${ }^{15}$ 
Due to a drive to improve cancer diagnosis and outcomes, the UK Department of Health and National Institute for Health and Care Excellence (NICE) have supported GPs having more access to imaging ${ }^{16-18}$ (including CT and MRI). However, direct access to brain imaging has not been widely taken up by GPs, ${ }^{19}$ despite a previous study showing that GPs report finding it valuable for patient management. ${ }^{20}$ One possible reason is that imaging may detect incidental findings (IFs) that may increase anxiety among GPs and patients. ${ }^{21}$ Another reason is the perception that neurological conditions are particularly difficult to manage. ${ }^{22}$

In the UK, some GPs have trained to become GPs with a special interest (GPwSI) in headaches. ${ }^{23}$ This training increases their knowledge and skills in diagnosis, investigation, including when to scan, and use of prophylactic medication. This reflects broader, international initiatives aiming to enhance specialist activity in primary care. ${ }^{24}$ GPwSIs also receive training in psychosocial factors impacting on headaches, as migraine is a biopsychosocial condition. ${ }^{25}$ A study found that GPwSIs in the UK scan less frequently for headache than neurologists typically do. ${ }^{26}$ In light of this, an educational intervention by GPwSIs might help GPs to employ direct-access imaging and potentially reduce unnecessary referrals and/or scans.

In this context, we need to understand GPs' perceptions about what would help them start using direct-access scanning for headache. The aim of this study is to describe GPs' attitudes towards and experiences of direct-access imaging for headaches. Additionally, we aimed to observe subjective responses to an educational session intended to improve GP knowledge and confidence in managing headaches, which was in the process of being delivered by a GPwSI to other GPs.

\section{METHODS \\ Design}

We used semistructured individual interviews to capture participants' views and experiences of the management of patients with headaches and use of direct-access MRI scans. This study was part of a larger, ongoing mixedmethods project comparing scans for headache received via direct access or a neurology referral. The project aims to describe and compare economic outcomes and patient satisfaction in the two care pathways. Qualitative methods are recommended as an essential component of complex interventions. They complement quantitative measures by helping to illuminate how and why an intervention 'works' or does not from the participant's perspective. ${ }^{27}$

\section{Educational intervention}

A GPwSI in headaches (RK) offered to visit GP practices in Lambeth and Southwark (London, UK) to deliver a 1-hour group presentation to staff. The talk was learner centred and was developed using NICE guidelines for headache management and a guideline for imaging suspected brain tumours in primary care developed by a national association of neurologists and GPs with an interest in headache. ${ }^{28}$ Advice centred on diagnosis, medication and use of direct-access scanning. RK also presented a holistic approach to headache management, integrating psychosocial factors that may impact headaches, including stress and comorbid mental health difficulties such as anxiety and depression. Handouts summarising key points were given to staff. This session was optional and did not affect eligibility in the qualitative study.

\section{Sample and recruitment}

The researcher (RU) contacted GPs and asked if they would be willing to take part in an interview. Those who agreed then spoke with the researcher alone at their practice or over the phone depending on their availability. The researcher approached practice managers from 17 GP practices in Southwark and 21 practices in Lambeth, which are two adjacent boroughs in South London, UK, with a combined population of 624745 inhabitants. Twenty GPs from 15 practices, out of a total of 68 GPs contacted in 45 practices, agreed to be interviewed. This was considered a purposive sample, as all participants were from boroughs with direct access to MRI scans, and their practices had been offered the educational talk. Only five participants in the sample attended the talk, owing to many GPs being unavailable during the scheduled presentation by Dr Kilner at their practices. Additionally, the project did not have the capacity to pursue GP practices who did not respond to the initial email invitation.

\section{Interviews}

Interviews were carried out by the first author RU, a male postdoctoral researcher who holds a PhD in Psychology, with prior training and experience in designing and conducting qualitative research. The interview protocol was developed through discussion between all authors. A flexible interview guide was developed based on the literature and the aims of the study. The guide was piloted with GPs and GPwSIs at group presentations. Themes and suggested changes arising from these presentations were then included in the interview guide. Broad topics and suggested probes were identified (see table 1). Participants were told beforehand that the focus of the interview was on patients they had seen with headaches who had been referred for a scan, either directly or via a neurology referral. The researcher was free to probe and clarify any issues arising spontaneously, which allowed participants to identify and explore issues of importance to them. Data saturation was reached with 20 interviews, with no new themes emerging. Interviews were tape recorded and lasted 30-50 min. The researcher's position was described to participants as an independent (ie, non-medical) researcher interested in their individual experiences of direct-access imaging for headaches and the educational talk. Participants were asked to recall a recent patient with headaches and how they managed them. 
Table 1 Interview topics and probes

\begin{tabular}{|c|c|}
\hline Question & Probe \\
\hline $\begin{array}{l}\text { Currently in your practice, how do you manage patients } \\
\text { who present with headache? }\end{array}$ & $\begin{array}{l}\text { Do you feel confident managing and diagnosing headache in } \\
\text { general practice? }\end{array}$ \\
\hline $\begin{array}{l}\text { How do you involve a headache patient in the decision- } \\
\text { making process? }\end{array}$ & What do you think is the impact of this? \\
\hline $\begin{array}{l}\text { How confident do you feel about diagnosis, management } \\
\text { and when to request a scan? }\end{array}$ & $\begin{array}{l}\text { When using open access, how would you explain results to } \\
\text { patients? }\end{array}$ \\
\hline $\begin{array}{l}\text { What impact do you think MRI direct access might have/ } \\
\text { has had on the number of people asking for them? }\end{array}$ & How about referrals to a neurologist? \\
\hline $\begin{array}{l}\text { How confident do you feel when evaluating risks/benefits } \\
\text { of different treatment options and outcomes? }\end{array}$ & $\begin{array}{l}\text { What difficulties do you have in resolving the patient's sense of } \\
\text { anxiety and uncertainty? }\end{array}$ \\
\hline $\begin{array}{l}\text { To what extent does the management of patients with } \\
\text { headache include a psychological approach? What } \\
\text { training do you have in psychology/psychiatry? }\end{array}$ & $\begin{array}{l}\text { How does mental health fit into general practice? What is your } \\
\text { approach to health anxiety? }\end{array}$ \\
\hline $\begin{array}{l}\text { Can you tell me about any headache patients who were } \\
\text { treatment resistant or difficult to manage? }\end{array}$ & $\begin{array}{l}\text { How much do you think this (heartsink) has affected your approach } \\
\text { (to headache) over time? }\end{array}$ \\
\hline
\end{tabular}

\section{Analysis}

Recorded data were transcribed and checked by RU and CP. Transcribed data were then entered into NVivo V.10, a qualitative software package. The original recordings were transferred to a secured computer and deleted from the audio recorder. Interview transcripts were first read in full by RU to gain an overall perspective of the data, and then coded line by line. Using a framework approach to thematic analysis, segments of text were put into a matrix, organised by theme and participant. ${ }^{29}$ Reliability was enhanced by two authors reading transcripts (RU and LR). This was followed by a discussion of codes, themes, charted summaries and interpretations between them. A draft of the analysed data was sent to participants to ensure they did not feel their confidentiality has been threatened or that they had been misquoted. Lack of response from everyone was taken to mean they had no objection to publication of their data. Four participants responded by email to report that the themes and quotes discussed accurately reflected their experience of their interview. The consolidated criteria for reporting qualitative research (COREQ-32) checklist guided the reporting of this study.

\section{RESULTS}

\section{Sample characteristics}

The sample age range was $31-66$ years, with a mean age of 45 years. No respondents refused to take part in the study; those contacted either responded and participated or were non-respondents.

\section{Theme one: management difficulties}

\section{Reassurance}

All 20 participants acknowledged that reassurance was an important factor in the decision to refer for a scan. If they had difficulty alleviating the patient's worry over a serious cause for their headaches, participants typically referred patients to a neurologist for a scan or requested a scan directly.

Most patients actually take your word for it, as long as you say 'yes I am pretty sure this is definitely not anything in the brain' ... but for those patients who are sort of intractable it is quite helpful. (P12)

However, a normal scan result was not the sole factor cited as influencing patient reassurance. Participants raised the issue that if patients perceive GPs as having less expertise than a specialist, this limits the reassurance they can provide. Six participants indicated that a key aspect of reassurance may be lost through direct-access scanning, if the patient does not see a specialist. One participant stated direct-access scanning may not save resources as patients may still request to see a specialist postscan:

... everybody wants to see a specialist, about whatever problem they have got... I am still trying to master that art of telling them they don't need to and reassuring them... But it is hard... with headache, people want to see a specialist (P15) 
Participant (P10) stated they would refer for a scan directly if it was primarily for reassurance and to a neurologist if they suspected a sinister underlying cause.

\section{Shared decision making}

Although participants had the intention of limiting unnecessary investigation, they also perceived themselves as more facilitators than gatekeepers. All participants found honesty about the limits of their knowledge aided collaboration with patients. One participant stated:

I am quite comfortable articulating... on my part not knowing what the problem is, but don't have an issue with articulating that to patients, and explaining how I'm then going to manage that... (P7)

Four participants spoke of patient empowerment as important to their management (P1, P11, P12 and P13). This was particularly crucial for patients who were likely to consult their GP on multiple occasions. For example:

I'd hope that (sharing treatment options) would empower the patient... I think that's a disadvantage... when you refer patients to a specialist, they might be seen once or twice in a specialist clinic, or the headache might be a long term problem, so they need somebody that can be relaxed and help them through it. (P11)

To facilitate patient empowerment, participants made themselves available as much as possible. One participant remarked:

... it's again leaving the door open, so... there is always a bit of safety netting about... 'if that happens then... just because I have said today I have not found anything when I have examined you, don't dismiss it and come back and the door is open'. (P19)

\section{Appointment length}

All participants said that patients with severe and/or chronic headaches often required longer appointments or that the short appointment time was typically not sufficient to cover everything. Six participants (P1, P5, P6, P13, P14 and P15) said that multiple consultations were a way to circumvent short appointment times. GPs typically left the door open for patients to book further appointments, with one participant (P15) reporting that they would sometimes book the subsequent appointment during the first consultation. Another explained that multiple consultations can help monitor their patient's evolving condition and facilitate shared decision making:

So the short answer is that you manage it longitudinally, across several appointments... something like a headache, you might start off by doing the simpler tests and making sure that you are (not) dealing with potentially sinister issues upfront... but on the basis that I will see you... either in a few days' time or next week and we just continue that conversation. (P5)

\section{Incidental findings}

All participants acknowledged that IFs were a source of anxiety for both patients and GPs, particularly for MRI rather than CT. Fourteen participants described warning patients of this possibility when discussing whether to scan, particularly if the scan was for reassurance. Negative consequences were patients subsequently become anxious or fixated on an IF, hindering reassurance.

Radiology reports themselves presented a potential source of difficulty for GPs, due in part to their lack of training in neurology. Although reports frequently came with a consultant's letter summarising and interpreting the findings, anxious patients sometimes asked for further explanation of reports. Five participants expressed a lack of clinical confidence in being able to explain these reports in detail to patients. Three participants had not had to do this in their careers and said they would not wish to do so. Nine participants would occasionally seek advice from the reporting radiologist if something was unclear in a report.

Four participants (P1, P3, P5 and P11) indicated that they would occasionally telephone a radiologist seeking further explanation for scan results. Two participants (P5 and P11) were aware the hospital has a dedicated room from which radiologists could answer any calls regarding reports.

Additionally, radiology reports varied in clarity. Three participants described instances where reports were very thorough but lacking in a clear guideline for interpretation. Some patients requested a copy of their report, seeking further explanation from their GP. One participant suggested that a more standardised format for reports would be helpful:

... it is quite helpful if it says 'normal intracranial appearances'. If it says:- 'abnormal appearance suggests discuss with neurologist'; ... Or 'ring for further advice' or so to highlight something needs further, 'in the opinion of a radiologist', or 'to have further follow up', I think is good. (P11)

One participant (P12) suggested that even if the radiologist's report did not recommend a scan, IFs or 'incidentalomas' may lead patients to request another in the future. One participant (P18) had used a National Health Service (NHS)-commissioned service provided by a private provider of imaging. The service reduced wait times, but the report was non-committal, as though the radiologists were not wanting to take responsibility for giving advice if an incidental abnormality was found.

\section{Mental health}

All but one participant reported that psychological comorbidity was common among patients presenting with headaches. Eighteen participants reported that their formal psychiatry training had been minimal, although they had received substantial on-the-job experience. They acknowledged finding it challenging to address 
psychological symptoms, when the patient had consulted for a physical concern. For example:

I personally find it quite a difficult therapy to sort of suggest to patients. I think it's quite difficult to get them on board with the, the fact that, sort of the psychosocial things might be a contributor to their headache or pain problems. (P10)

The two participants who did not experience difficulty in addressing psychological symptoms had received some formal training. Nonetheless, all participants acknowledged the necessity of addressing mental health difficulties. One participant observed:

You actually you can do more harm to somebody, I think by going down a very physical route and not addressing their psychological (issues)... (P8)

Potentially facilitating this process was them having good access to mental health services. All participants were aware of and referred patients to Increasing Access to Psychological Therapies (primary care service delivering evidence-based treatments for anxiety and depression) and/or other mental health services. Three participants reported that their practice had an in-house psychologist. Two participants responded that a normal scan result can help move the management discussion forwards by relieving anxiety (P19 and $\mathrm{P} 6)$ :

... once patients have a normal scan, then they can focus on kind of moving forward with management and are more willing to try tablets and medication regimes, because lots of people don't like taking tablets. (P19)

However, this benefit did not necessarily extend to more severe cases. One participant observed:

... headache can be part of an overall difficult problem amongst a number of other complex problems the patient has. (P11)

Another participant observed that in complex cases, such as patients with medically unexplained symptoms (MUS), neither a scan nor a specialist referral help resolve problems:

I have got a (patient) with chronic fatigue syndrome, back-ache, that comes backwards and forwards, with headache and (she) can't see that it is related to her mood. She is definitely depressed. So she has actually been to see a neurologist already, and still comes back with a headache. So it is all related to her mood and she is not willing to accept that. (P15)

For these patients, shifting the discussion towards mental health, while difficult, was more helpful in the long term, with one participant reporting the following:

... this particular person that I mentioned, it took me a year to actually get him to accept that it was a mental health issue rather than a physical problem. But the moment I got him to accept that, his A \& E (Accident and Emergency) attendance and GP attendance fell by about $250 \% \ldots$ (P3)

\section{Theme two: reasoning biases}

Impact of family and media

Seven participants (P11, P12, P13, P15, P18, P19 and P20) acknowledged the impact of web-based information can have on patients' worry. However, this also provided empowerment when used discerningly, something that participants could facilitate. For example:

... it is part of general practice... there are lots of... verified web sources as well so it is directing patients to things that you know are valid. The internet is full of information and not all of it is appropriate... (P19)

Five participants described the influence of family on patient worry (P13, P15, P18, P19 and P20), for example, a relative having an aneurysm after suffering headaches for a period of time:

... people might know a friend or have a family history... who has had... some sort of brain problem like an aneurism... those are people who might come more directly and say... I'm worried what this headache could be and... they are thinking 'this is not just a migraine'. (P18)

\section{Managing uncertainty}

Seventeen GPs indicated that requesting a scan could decrease their uncertainty. For example:

... when there are some features about the headache... that I think are slightly unusual and don't fit a particular pattern, and I can't clinically say 'oh I am really sure it is that type of headache', that's when it would be useful. (P14)

There was variation in their tolerance of uncertainty. Eight experienced GPs valued their sense of toleration for uncertainty. One of these eight participants illustrated a typical scenario where this changed their management:

They walk out of your room no better than when they walked in. They may need a scan, they may be right. And it's just always keeping an open mind... let's live with the uncertainty and let's see you in three weeks' time, maybe you could keep a diary between now and then, I really want see the pattern of these headaches. And then it is, whoops, it is every morning... and it's a consistent pattern and it does seem to be relieved by paracetamol which you would expect chronic daily headache to be... Maybe I need to reconsider my own initial working diagnosis. (P1)

One participant who reported lower tolerance for uncertainty also expressed lower clinical confidence regarding headache management: 
Headaches I suppose, if a GP has 'neurophobia' it is probably because whatever treatment they are giving isn't working, or because they are worried that every patient that comes through the door with a headache has a brain tumour for whatever reason. (P16)

The relationship between tolerance for uncertainty and a tendency to refer for a scan was complex. Two participants indicated that due to a low tolerance for uncertainty, they primarily stuck to guidelines that discourage scans for reassurance:

I tend to be quite conservative... looking for red flags and, and just sort of examining and managing that way. (P6)

Conversely, four reporting a low tolerance for uncertainty said they referred for a scan for fear of missing something serious. This variation across participants may be partly explained by a negative influence from a prior experience. One participant described the impact of seeing a patient without red flags that ended up having a brain tumour:

You tend to swing to the very, very risk averse side of things when you have those experiences, and then it slowly... you come back to the middle as it were. (P3)

Another participant observed that difficult or 'heartsink' patients, who visited frequently with non-specific difficult-to-treat symptoms, might influence them to order a scan in the absence of clinical indicators. The management of uncertainty for participants was also impacted by their patient's uncertainty. For example:

... there may be patients who are more difficult to manage, patients who have personality disorders... they can't cope with uncertainty in any sense... if a patient is very demanding in that way, it puts emotional pressure on the doctor which it inevitably will, then you are more likely to organise a scan. (P11)

\section{Theme three: system issues}

\section{Change in services}

One participant noted that patients were now more likely to expect imaging technology as part of investigation into their chronic pain:

... patients now come along with all sorts of things wanting a scan, be it headache or knee pain or back pain etc. so I think there is an issue around patient expectation. (P10)

\section{Cost}

Participants' perceptions were mixed regarding potential costs. For example:

if you are the sort of GP that... feels the responsibility on the purse strings... then I suppose that adds an extra layer of complexity to... the decision making process. (P16) ...if I put my 'wider -health-system-cost-hat' on I would be a little concerned about that... But... the idea is still a good one because I think that the evidence suggests that actually it is cost-effective, if my recollections are correct. (P3)

\section{Legal}

Two participants made explicit reference to GPs' fears regarding legal action as a factor. For example:

I think increasingly the medical/legal landscape is very clear cut... we are getting... more and more at risk of being complained against and sued, it is not a problem of being complained against or sued but the time taken to resolve these things. (P13)

\section{Discerning use of direct access}

Two participants (P11 and P19), who had received further training in headaches, reported that direct-access scanning should come packaged with an educational component on headache diagnosis and management and on interpreting scan results:

I think you will need some guidelines to say, 'these are the real red flag lines' 'these are more yellow flags' so that..., GPs are aware which patients they should be thinking of... (P11)

They believed that tolerance of uncertainty, difficulty managing 'heartsink' patients and lack of clinical confidence could all be ameliorated through further training, with an emphasis placed on adopting a holistic approach.

So there probably needs to be... some kind of protocols about, when it is appropriate to refer or things to try first. (P19)

\section{Education on headache provided by GPwSI}

Five participants had attended the educational intervention. All five reported that it had a positive impact on their treatment of headaches. Increased knowledge about diagnosis and management of chronic daily headache as well as analgesia overuse were specifically cited as key outcomes of the talk:

... ever since that conversation I have spent much more time when someone talks about a headache trying to work out whether these two issues (diagnosis/ analgesia overuse) are predominant. (P5)

Four out of the 20 participants were unaware of the current direct-access pathway. One of them was unaware of the local policy of providing direct-access MRI (P15). Two participants had relied on NHS-purchased private providers in the past for direct-access MRI (P6 and P18). One participant indicated that their practice was not made aware of local direct access until the educational talk by a GPwSI (P1). A further three participants were aware of new direct-access MRI but rarely used it or 
preferred direct-access CT scans, which were available previously (P8, P10 and P11).

\section{DISCUSSION}

\section{Summary}

GPs placed value on direct-access scanning according to whether it had facilitated their management of patients with headache. Overall, GPs favoured a management style that emphasised patient empowerment and facilitation of access to specialist services, rather than gatekeeping. Echoing previous findings, ${ }^{3}$ all GPs recognised using direct-access scans to reassure patients' concerns over a serious underlying cause for their headaches. There was evidence that patients' worries were sometimes exacerbated by the media, their family and health anxiety. A normal scan result often helped resolve uncertainty for both patient and GP and moved management forwards in the direction of preventative treatment. However, successful reassurance did not always extend to patients with mental health difficulties and/or severe symptoms, consistent with previous findings. ${ }^{15}$

GPs' tolerance of uncertainty was influenced by length of experience, clinical confidence and prior (negative) experiences. This in turn affected whether GPs referred patients to a specialist, requested a scan directly or monitored their symptom development over multiple consultations to delay referral.

A potentially remediable finding was that GPs sometimes had difficulty with radiology reports being too detailed or lacking a clear guideline, particularly in the case of IFs. ${ }^{30}$ Regarding the educational talk, those who received it gained knowledge in diagnosis and medication, which they reported as improving their management.

\section{Strengths and limitations}

Care was taken to conduct the interviews in an informal and conversational manner. The rapport achieved with GPs suggested that responses were candid and personal rather than socially desirable. Participants were drawn from practices in deprived urban areas of South London. While this produced data from busy clinics in highly diverse, densely populated areas, this limits generalisability. Of the 45 GP practices approached, 30 of these did not yield participants, potentially introducing sample bias due to non-respondents' perspectives going unheard. Another limitation is that data were solely captured via self-report, rather than direct observation of consultations. GPs' accounts of their patients could not be corroborated. Only a small number of participants took part in the educational intervention, limiting the ability to draw out generalisable outcomes. However, the sample and methodology used in this study fall within guidelines on qualitative methods, which aim to elicit in-depth perspectives that are not possible to obtain in an RCT. ${ }^{31}$ Finally, it should be noted that healthcare systems around the world vary widely, with primary care physicians' decision making likely affected by multiple factors such as insurance, copayment or legal proceedings. Therefore, this research requires replication in other healthcare systems with direct-access pathways, such as the USA and Canada.

\section{Implications for research and practice}

Many participants reported scanning for reassurance. Despite scans for reassurance not being advised by NICE, ${ }^{32}$ this finding and its implications are important to consider. Direct-access imaging was not the sole means of reassuring anxious patients, but when used discerningly, it facilitated management and eliminated the need for a specialist referral. Making the availability of direct-access imaging services known should be a target for service development.

A potential risk of scanning is the significant likelihood of IFs. ${ }^{33}$ GPs expressed difficulty in communicating IFs to patients. According to a meta-analysis of international research, ${ }^{34}$ IFs in clinical brain imaging are common, particularly when using high-resolution MRI scans. Despite the relatively higher prevalence of IFs in body MRI scans, ${ }^{33}$ IFs in brain imaging are a considerable cause of concern for patients and clinicians. ${ }^{21}$ This highlights the potential need for more uniform reporting guidelines, an approach that proved successful in a recent study. ${ }^{14}$ Additionally, easy access to a neuroradiologist for advice may also help reduce GPs' fears of explaining radiology reports. A recent study in Canada revealed that infrequent communication between family physicians and radiologists regarding the interpretation of scan results may contribute to poorer care. ${ }^{35}$

An interesting finding was that some participants worried that patients referred for a scan directly may still wish for a specialist referral after receiving their results. Despite this fear, the available data would suggest that rates of onward referral after a direct-access scan are low and that these scans may, in line with other evidence, be cost-saving. ${ }^{12-1420}$ This remains to be demonstrated in the second part of our mixed-methods study. Nonetheless, these participants' fears related to the theme of reassurance. It has previously been argued that part of the reassurance patients receive may come from what the neurologist tells them, rather than the scan. ${ }^{36}$ An RCT examined reassurance postscan for anxious patients in a headache clinic. ${ }^{15}$ While initially reassured by the scan, after a year, patients reported similar levels of worry. This may suggest that patients high in anxiety may benefit from psychological intervention, ${ }^{37}$ which a scan cannot replace. Interestingly, despite their worry levels remaining high at the end of the RCT, patients given a scan cost significantly less than those in the control group due to reduced service use. ${ }^{15}$

For some GPs, shifting the focus from physical to psychological symptoms facilitated successful management of patients with mental health difficulties or MUS. Greater attention to treating both headache and psychological symptoms in primary care, as well as easy access to community mental health services, may help limit 
cycles of unnecessary investigation. Multidisciplinary approaches, typically employed in pain clinics, have shown efficacy for headache. ${ }^{38}$ Implementing such an integrative approach in primary care is challenging, given short appointment times and limited continuing medical education. Nonetheless, direct-access scanning could play an important role in this if it were framed as facilitating integrative care. This may be particularly valuable in the context of IFs. A recent study interviewed senior neurologists in Edinburgh about the impact of IFs on their workload. ${ }^{39}$ Neurologists reported that patient anxiety often needed addressing before treatment options could be discussed. If such distress could be effectively managed in primary care, this could reduce workload and wait times for specialists, although this remains to be investigated. Additionally, for patients whose anxiety is too severe to benefit solely from an MRI scan, cognitive-behavioural therapy for migraines is currently being trialled. ${ }^{40}$

'Neurophobia', a term coined by American clinician Jozefowicz to describe medical students' lack of confidence around neurology, ${ }^{41}$ has also been applied to medical students, junior doctors and GPs in the UK. ${ }^{22} 4243$ The majority of interviewees acknowledged experiencing neurophobia at one time or another. This perceived lack of competence could be helped through better training, both during medical school and once qualified, as recently reported in Finland. ${ }^{44}$ The educational talk focused on headache diagnosis and holistic management, including how to avoid triggers, recommended psychological treatments, medication, how to offer reassurance, managing risk and the option of referral for scanning. The impact of this on GPs' management may be to facilitate reassurance without referral. An educational component rolled out alongside direct-access scanning, emphasising a holistic approach that empowers and reassures patients, may be as important as more traditional teaching around diagnosis and medication. A recent study in Estonia found positive outcomes following an educational intervention aimed at reducing unnecessary neurology referrals by GPs for headaches. ${ }^{45}$ Education around discerning use of open-access scanning may also benefit countries where family physicians have been found to overuse diagnostic imaging, such as Canada. ${ }^{46}$ When used appropriately, direct access may be another tool for GPs to facilitate empowerment and reassurance. Given the small number of participants receiving the talk in this study, further research is required to assess this.

\section{CONCLUSIONS}

GPs' accounts of the difficulties in using direct access related closely to general difficulties in managing patients with headaches, underlining the value of education around headache diagnosis and management. Uptake of direct-access scanning by GPs has been slow. Based on the perceptions of GPs, increased accessibility to direct-access scans, training by GPwSIs in headache management, ways to address mental health difficulties with patients and standardised reporting of scans may all facilitate this uptake.

Acknowledgements The authors wish to acknowledge Mark Ashworth and Alison McKinlay for providing important feedback on our manuscript, Gabriella Wojewodka for the help in drafting the protocol, Carly Pearson, for the work in transcribing and checking recorded interviews and our participants.

Contributors RU: design, data collection, analysis, interpretation, write-up, editing, final approval and agreement to be accountable for integrity/accuracy of content. RK: design, data collection, interpretation, revising of content, final approval and agreement to be accountable for integrity/accuracy of content. LR: design, analysis, interpretation, revising of content, final approval and agreement to be accountable for integrity/accuracy of content.

Funding This work was supported by the Guy's and St Thomas' Charity but not through a specific grant. This project is part of the Transforming Outcomes and Health Economics through Imaging (TOHETI) programme.

Disclaimer The views expressed are those of the authors and not necessarily those of our funders or collaborators.

Competing interests None declared.

Ethics approval Ethical approval was obtained from the Psychiatry, Nursing \& Midwifery Research Ethics Subcommittee at King's College London (LRS-14/150662) and written consent obtained from all participants.

Provenance and peer review Not commissioned; externally peer reviewed.

Data sharing statement Extra data can be accessed via the Dryad data repository at http://datadryad.org/ with the doi:10.5061/dryad.p6n8f.

Open Access This is an Open Access article distributed in accordance with the Creative Commons Attribution Non Commercial (CC BY-NC 4.0) license, which permits others to distribute, remix, adapt, build upon this work non-commercially, and license their derivative works on different terms, provided the original work is properly cited and the use is non-commercial. See: http://creativecommons.org/ licenses/by-nc/4.0/

(c) Article author(s) (or their employer(s) unless otherwise stated in the text of the article) 2017. All rights reserved. No commercial use is permitted unless otherwise expressly granted.

\section{REFERENCES}

1. Stovner L, Hagen K, Jensen R, et al. The global burden of headache: a documentation of headache prevalence and disability worldwide. Cephalalgia 2007;27:193-210.

2. Latinovic R, Gulliford M, Ridsdale L. Headache and migraine in primary care: consultation, prescription, and referral rates in a large population. J Neurol Neurosurg Psychiatry 2006;77:385-7.

3. Morgan M, Jenkins L, Ridsdale L. Patient pressure for referral for headache: a qualitative study of GPs' referral behaviour. Br J Gen Pract 2007;57:29-35.

4. Ridsdale L, Clark LV, Dowson AJ, et al. How do patients referred to neurologists for headache differ from those managed in primary care? Br J Gen Pract 2007;57:388-95.

5. Hamilton W, Kernick D. Clinical features of primary brain tumours: a case-control study using electronic primary care records. $\mathrm{Br} J \mathrm{Gen}$ Pract 2007;57:695-9.

6. Kernick D, Stapley S, Goadsby PJ, et al. What happens to new-onset headache presented to primary care? A case-cohort study using electronic primary care records. Cephalalgia 2008;28:1188-95.

7. Ridsdale L, Noble AJ, Nadeem F, et al. Headache: the patient's view. J Neurol Neurosurg 2014;01:5.

8. Underwood R, Kennis K, Ridsdale L. Achieving a balance between the physical and the psychological in headache. $\mathrm{Br} J$ Gen Pract 2017;67:374-5.

9. Ridsdale L, Mtandabari S, Noble A. 038 Referral patterns to neurology: past, present and future. J Neurol Neurosurg Psychiatry 2012;83:e203-1.

10. McCrone P, Seed PT, Dowson AJ, et al. Service use and costs for people with headache: a UK primary care study. J Headache Pain 2011;12:617-23.

11. RCP. Local adult neurology services for the next decade. London: Royal College of Physicians, 2011.

12. Simpson GC, Forbes K, Teasdale E, et al. Impact of GP direct-access computerised tomography for the investigation of chronic daily headache. Br J Gen Pract 2010;60:897-901. 
13. Thomas R, Cook A, Main G, et al. Primary care access to computed tomography for chronic headache. Br J Gen Pract 2010;60:426-30.

14. Taylor TR, Evangelou N, Porter H, et al. Primary care direct access MRI for the investigation of chronic headache. Clin Radiol 2012;67:24-7.

15. Howard L, Wessely S, Leese M, et al. Are investigations anxiolytic or anxiogenic? A randomised controlled trial of neuroimaging to provide reassurance in chronic daily headache. J Neurol Neurosurg Psychiatry 2005;76:1558-64.

16. Health Do. Our health, our care, our say: a new direction for community services. London: The Stationery Office, 2006.

17. Health Do. Direct access to diagnostic tests for cancer, 2012.

18. NICE. Referral guidelines for suspected cancer, 2015. https://www. nice.org.uk/guidance/CG272005https://www.nice.org.uk/guidance/ CG27 (accessed 18 May 2016).

19. Sibbald B. Direct access to diagnostic services. Br J Gen Pract 2009;59:144-5

20. Apthorp LA, Daly CA, Morrison ID, et al. Direct access MRI for general practitioners-influence on patient management. Clin Radiol 1998;53:58-60.

21. Kernick D, Williams S. Should GPs have direct access to neuroradiological investigation when adults present with headache? Br J Gen Pract 2011;61:409-11.

22. Schon F, Hart P, Fernandez C. Is clinical neurology really so difficult? J Neurol Neurosurg Psychiatry 2002;72:557-9.

23. Ridsdale L, Doherty J, McCrone P, et al. A new GP with special interest headache service: observational study. Br J Gen Pract 2008;58:478-83.

24. Winpenny E, Miani C, Pitchforth E, et al. Outpatient services and primary care: scoping review, substudies and international comparisons. Health Services and Delivery Research 2016;4:1-290.

25. Cousins S, Ridsdale L, Goldstein LH, et al. A pilot study of cognitive behavioural therapy and relaxation for migraine headache: a randomised controlled trial. J Neurol 2015;262:2764-72.

26. Elliot S, Kernick D. Why do GPs with a special interest in headache investigate headache presentations with neuroradiology and what do they find? J Headache Pain 2011;12:625-8.

27. Craig P, Dieppe P, Macintyre S, et al. Developing and evaluating complex interventions: the new Medical Research Council guidance. BMJ 2008;337:a1655

28. Kernick DP, Ahmed F, Bahra A, et al. Imaging patients with suspected brain tumour: guidance for primary care. $\mathrm{Br} J$ Gen Pract 2008;58:880-5

29. Ritchie J, Spencer L, O'Connor W. Carrying out qualitative analysis. Qualitative research practice: A guide for social science students and researchers, 2003:219-62.
30. Hayward R. VOMIT (victims of modern imaging technology)-an acronym for our times. BMJ 2003;326:1273.

31. Green J, Thorogood N. Qualitative methods for health research: Sage, 2013.

32. NICE. Headaches overview. http://pathways.nice.org.uk/pathways/ headaches2015 (accessed 16 June 2016).

33. Booth TC, Najim R, Petkova $\mathrm{H}$. Incidental findings discovered during imaging: implications for general practice. $\mathrm{Br} J$ Gen Pract 2016;66:346-7.

34. Morris Z, Whiteley WN, Longstreth WT, et al. Incidental findings on brain magnetic resonance imaging: systematic review and metaanalysis. BMJ 2009;339:b3016.

35. You JJ, Levinson W, Laupacis A. Attitudes of family physicians, specialists and radiologists about the use of computed tomography and magnetic resonance imaging in Ontario. Healthcare Policy $2009 ; 12$.

36. Fitzpatrick R, Hopkins A. Referrals to neurologists for headaches not due to structural disease. J Neurol Neurosurg Psychiatry 1981;44:1061-7.

37. Sullivan A, Cousins S, Ridsdale L. Psychological interventions for migraine: a systematic review. J Neurol 2016:1-9.

38. Gaul C, Liesering-Latta E, Schäfer B, et al. Integrated multidisciplinary care of headache disorders: a narrative review. Cephalalgia 2015.

39. Booth TC, Boyd-Ellison JM. The current impact of incidental findings found during neuroimaging on neurologists' workloads. PLoS One 2015;10:e0118155

40. Morgan M, Cousins S, Middleton L, et al. Patients' experiences of a behavioural intervention for migraine headache: a qualitative study. $J$ Headache Pain 2015;17:1.

41. Jozefowicz RF. Neurophobia: the fear of neurology among medical students. Arch Neurol 1994;51:328-9.

42. Ridsdale L. No more neurophobia: welcome neurology in general practice. Br J Gen Pract 2009;59:567-9.

43. Thapar AK, Stott NC, Richens A, et al. Attitudes of GPs to the care of people with epilepsy. Fam Pract 1998;15:437-42.

44. Ansakorpi H, Sumelahti ML, Kaasila R. Medical students' experience of emotions and success in neurological studies -what do they tell us? BMC Med Educ 2017;17:68.

45. Braschinsky M, Haldre S, Kals M, et al. Structured education can improve primary-care management of headache: the first empirical evidence, from a controlled interventional study. J Headache Pain 2016;17:24.

46. Wintemute K, McDonald K, Huynh T, et al. Addressing overuse starts with physicians: choosing Wisely Canada. Can Fam Physician 2016;62:199-200. 